\title{
Latim e retórica nos sermões de Vieira: o Sermão XIV do Rosário
}

\author{
Ronald FERreira da CoSTA \\ Universidade Estadual de Londrina \\ Brasil
}

\begin{abstract}
Resumo. Maria de qua natus est Jesus, qui vocatur Christus é a epígrafe do Sermão XIV do Rosário, corpus da pesquisa "O Latim como elemento de Retórica nos Sermões do Padre Antônio Vieira”, cujo parcial resultado aqui apresento. Da epígrafe, o autor extrai três natos de Maria: Jesus, São João e os "Pretos" devotos, sendo a mesma mãe, mas o parto diverso; num, isenta da dor na manjedoura, noutro, excruciada 'cruciabatur ut pariat' - no calvário quando nasce o Salvador e ganha, ali, os outros filhos: 'Ecce fillius tuus', para São João e 'Populus Aethiopium hi fuerunt illic', para o povo etíope. Destes, por conseguinte, três respectivas obrigações de amar, servir e venerar a Virgem. Procuro demonstrar como as citações latinas estruturam todo o arcabouço retórico de Vieira, basilares de uma cabal compreensão.
\end{abstract}

Palavras-Chave. Sermão; latim; retórica; Maria; "pretos” devotos.

O "Sermão XIV do Rosário", de autoria do Padre Antônio Vieira', foi pregado pelo próprio autor - o que doravante se tonaria uma praxe - na Bahia, no ano de 1633, aos negros de um Engenho. Fato relevante é a conjuntura de ser a primeira pregação em público realizada por Vieira, antes mesmo dos seus votos sacramentais. Percebe-se, todavia, já bem consolidada sua retórica sui generis, amiúde explorada em toda a sua produção, a despeito das escusas que humildemente insere no exordio ${ }^{2}$ do Sermão.

\section{Email: ronaldvs.f@hotmail.com}

Artigo baseado em comunicação apresentada durante o XVI Congresso Nacional de Estudos Clássicos, Ócio \& Trabalho no Mundo Antigo (Araraquara, Brasil, 3-7 de setembro de 2007) e desenvolvido através do projeto de pesquisa "Estudos de Retórica Clássica: Disputatio de Rhetorica de Alcuíno e Sermões de Vieira”, realizado na Universidade Estadual de Londrina. Orientador: Prof. Dr. João Bortolanza.

${ }^{1}$ Sermão XIV do Rosário: Os três filhos de Maria, in Antônio VIeIRA, Sermões: Padre Antônio Vieira, vol. 2, org. e introd. Alcir Pécora, São Paulo, Hedra, 2000, p. 635-58. Para traduções das breves citações latinas, todas extraídas da referência anterior, e indicação das respectivas páginas, vide apêndice.

${ }^{2}$ Para definições dos termos latinos de Retórica, vide glossário. 
A análise aqui realizada não tem a pretensão de esgotar toda a estrutura retórica, perpassando cabalmente sua estilística e seus tropos - o que seria labor hercúleo - mas, através das recorrentes citações latinas, desconstruir sua dispositio, a fim de vislumbrar sua inventio, conjecturando então, com alguma propriedade, o processo de estruturação desse cânone retórico.

O panegírico é construído numa forma bipartite. Em cada uma dessas partes, por sua vez, encontramos uma subestrutura tripartite, já prenunciadas nas respectivas partições ${ }^{3}$, onde distribuem-se os loci argumentationis, em geral, extraídos da Vulgata, porquanto que sempre apresentados em Latim.

O exordio, entretanto, só preludia a primeira parte dessa estrutura, contextualizando o espectador da importância do dia em comemoração a São João Evangelista - daí justifica-se o panegírico - que coincidirá, segundo a conjuntura, com o "dia e a festa da Senhora do Rosário" e dos "Pretos seus devotos", ao dia 27 de dezembro.

Narratio I. Maria de qua natus est Jesus, qui vocatur Christus é, além de epígrafe que permeia todo o Sermão, cláusula e tema com a qual Vieira inicia sua narração, já extraindo dela o significado de outro nascimento que não em 25 de dezembro. Para tanto, distingue em significados metalingüísticos os nomes Cristo e Jesus, respectivamente, ungido e salvador. Os loci que se seguem tratam dos partos da Santíssima Maria, na manjedoura e no Calvário.

Narratio II. Para extrair da mesma epígrafe o significado do nascimento de São João como filho da Virgem - e esse é o propósito dessa narratio - Vieira considera o qui vocatur Christus impróprio, uma vez que o verbo contradiz o fato de ter sido chamado, no dia da circuncisão, já revelado pelo anjo, de Jesus; e o Christus, supérfluo, já que só serviria para distinguir um Jesus de outro Jesus, e assim é. Ecce filius tuus é, portanto, o loci dessa parte, além de buscar, também, aqui, autoridade em máxima da filosofia antiga.

Narratio III. ... Aethiopium hi fuerunt illic é um loci no qual este illic, o autor interpreta como "ali" de "ali no Calvário". Refere-se, portanto, aos "Pretos" etíopes que, por meio do batismo, nascem como filhos da Virgem quando nasce o Salvador no Calvário, pela perspectiva de que os batizados tornam-se 'membros de Cristo' e, se Maria é mãe, tanto da cabeça como dos membros, é mãe também, dos negros devotos.

\footnotetext{
${ }_{3}^{3}$ Ambas as partições apresentam-se como Narratio I, II e III.
} 
Propositio. Aqui o autor demonstra sua posição na defesa da idéia da necessidade da devoção ao Rosário.

Narratio I. Respaldado pela Vulgata, aqui Vieira persuade os Negros da idéia de que Deus os escolhera para salvar com o batismo e que, por conta disso, devem a incondicional devoção a Maria.

Narratio II. Os salmos atribuídos a Davi são alguns dos loci apresentados para refutar as possíveis escusas dos "Pretos" em rezar o Rosário advindas do exaustivo e ininterrupto labor nos Engenhos. 'Pro torcularibus filiis Core' indica aqueles que foram compilados e reduzidos por Davi com o fim de que trabalhassem orando.

Em seguida, traça um paralelo comparativo entre as penúrias de Cristo no Calvário e a dos "Pretos" no Engenho e se meditarem na Virgem como Jesus o Fez na Cruz, 'quão adoçada ficará a dureza e quão enobrecida a vileza dos vossos trabalhos...' (p. 652). Por fim, nessa parte, o autor demonstra os três Mistérios gozosos, dolorosos e gloriosos em que está repartido o Rosário.

Narratio III. Após o comparativo das penas na narratio anterior, Antônio Vieira ensina, aqui, que os Mistérios dolorosos são os que mais pertencem à condição dos "Pretos" do Engenho como os gozosos aos seus Senhores, pois, sic vos non vobis mellificatis apes. Mas, conclui essa narratio citando 'mais inveja devem ter vossos senhores às vossas penas, do que vós aos seus gostos’ (p. 658), já que só os que penam nos Mistérios dolorosos aqui, poderão desfrutar dos gloriosos e gozosos na vida eterna.

Peroratio. Nesta peroratio Vieira retoma sinteticamente o cerne de todo este Sermão exaltando, ainda, a condição dos "Pretos" devotos (p. 658): 'nem podeis desejar maior honra nos vossos desprezos, nem maior alívio nos vossos trabalhos', e conclui numa retomada de raciocínio interpretativo: Maria de qua natus est Jesus, qui vocatur Christus.

O mais relevante resultado obtido na facção desta análise pelo já citado processo de desconstrução da dispositio foi compreender e poder demonstrar que as diversas citações em Latim, como loci para a argumentatio, são, além de imprescindíveis, auto-suficientes para a compreensão da obra no seu sentido mais profundo e cabal. Desse modo, entendemos que, aquilo que num senso comum, destituído do Latim, parece ser o todo que a obra tem a oferecer, não passa de uma amplificatio do sustentáculo retórico, o Latim. 


\section{Apêndice ${ }^{4}$}

Epígrafe: Maria de qua natus est Jesus, qui vocatur Christus (Mt. 1.16, apud Vieira, p. 635).

Propositio I. Maria de qua natus est Jesus, qui vocatur Christus, "Maria da qual nasceu Jesus, que é chamado Cristo" (idem, p. 636).

Partitio. $\mathrm{O}$ autor inicia o roteiro da narratio em três etapas interpretativas da epígrafe acerca dos nascimentos de Maria no Calvário. O segundo parto de Maria a Jesus, o parto a São João e aos "Pretos", seu devotos.

Narratio I. Trata do segundo nascimento de Jesus, no Calvário.

Maria de qua natus est Jesus, qui vocatur Christus (idem, p. 637). Distingue Cristo (ungido) de Jesus (salvador). É Cristo porque foi ungido. É Jesus porque foi salvador (idem, ibidem).

Antequam parturiret, peperit: antequam veniret partus ejus, peperit masculum (Is 66.7, apud Vieira, p. 637), "antes que estivesse de parto, ela deu à luz; antes que lhe viessem as dores, ela deu à luz um filho".

Qui audivit unquam tale, et quis vidit huic simule? (Is 66.8, ibidem), "quem jamais ouviu tal coisa? Quem ouviu coisas semelhantes?"

Cruciabatur ut pariat; et pepěrit filium mascŭlum, qui recturus erat omnes gentes (Ap 12.2-5, apud Vieira, p. 638), "escruciava de dor para parir; e deu à luz um filho, um varão, que havia de reger todas as nações".

Mas se o parto da mesma Virgem foi isento de toda dor e moléstia; que dores e que tormentos são estes com que agora S. João a viu parir, não outro, senão o mesmo filho? A palavra Cruciabatur, que é derivada da Cruz, basta por comento de todo o texto (...) Era o segundo nascimento do filho (...) e com os braços pregados nos de uma Cruz: por isso a mesma Cruz do nascimento do filho foi também a Cruz do parto da mãe: Et cruciabatur ut pariat (p. 638-9).

Quia natus est vobis hodie Salvator, qui est Christus ${ }^{5}(.$.$) Notai$ que não disse: Qui est Salvator, assim como disse: Qui est Christus: porque o menino nascido já era Cristo, mas ainda não era Salvador. Havia de ser Salvador, e para ser Salvador, nascia, mas ainda o não era (p. 639).

${ }^{4}$ Excertos da inventio do Sermão na ordem da dispositio.

${ }^{5}$ Lc 2.11: "pois vos nasceu hoje o Salvador, que é Cristo". 
Narratio II. Trata do nascimento do segundo Filho da Virgem Maria, São João.

Quando o mesmo Cristo estava na Cruz, disse à sua Santíssima Mãe: Ecce filius tuus ${ }^{6}(. .$.$) com os olhos e com a inclinação da cabeça, que$ só tinha livre, apontando para João (p. 640).

Amicus est alter ego (máxima da filosofia antiga, apud Vieira, $\mathrm{p}$. 640), "o amigo é o outro eu".

Non errasti mater, namque; et hic Alexander est, "não erraste, mãe, porque este também é Alexandre" (apud Vieira, p. 640-1).?

Narratio III. Trata do nascimento dos "Pretos" devotos de Maria, como filhos seus.

Homo, et homo natus est in ea, et ipse fundavit eam Altissimus (S1 86.5, apud Vieira, p. 642), “o homem e o homem nasceram ali, e o mesmo Altíssimo a estabelecerá".

Um destes homens nascidos de Maria é Deus; o outro homem também nascido de Maria (...) é todo homem que tem a fé e conhecimento em Cristo (...) ainda que a cor seja tão diferente (...) como é a dos pretos (...) De maneira que vós os Pretos, que tão humilde figura fazeis no mundo, e na estimação dos homens (...) estais escritos e matriculados nos livros de Deus (...) e não com menos título (...) que de filhos da Mãe do mesmo Deus: Et populus Aethiopum hi fuerunt illic ${ }^{8}$ (p. 642).

Magni Sacramenti est, ut dicantur filii Core, quia Core interpretatur Calvaria. Ergo filii passionis illius, filii redempti sanguine illius, filii crucis illius (August. Serm. 41, in Psalmum XLI Enarratio, sermo ad Plebum, apud Vieira, p. 643), "é do Grande Sacramento, que sejam chamados de filhos de Coré, porque Coré é interpretado por Calvário. Portanto, eles, filhos da paixão dele, filhos redimidos pelo sangue dele, filhos da cruz dele".

Coré, na língua hebréia, quer dizer Calvário (...) assim ao pé da Cruz nasceram também (...) os Pretos (...) Os Etíopes de que fala o texto, não são todos os Pretos universalmente (...) mas fala somente daqueles que (...) por virtude do batismo são Cristãos (...) Porque (...) são membros de Cristo (p. 643-4).

Sicut enim corpus unum est, et membra habet multa, omnia autem membra corporis, cum sint multa, unum tamen corpus sunt; ita est

6 Jo 19.27: "eis aí o teu filho".

${ }^{7}$ Palavras de Alexandre Magno à sua mãe, que o confundira com Efestião ao voltarem da guerra.

${ }^{8}$ S1 3.4: "e o povo da Etiópia que é nascido ali". 
Christus. Etenim in uno spiritu omnes nos in unum corpus baptizati sumus (Santo Agostinho, apud Vieira, p. 643), "porque, assim como o corpo é um, e tem muitos membros, e todos os membros do corpo, como sendo muitos, são um só corpo, assim é Cristo também. Pois num único espírito e num único corpo somos todos batizados".

In uno salvatore omnium Jesu, plurimos Maria peperit ad salutem. Eo ipso quod mater est capitis, multorum membrorum Christi, quia caput et corpus unus est Christus. ${ }^{9}$

(Em um só salvador de todos, Jesus; Maria pariu muitos para a salvação. Por isso mesmo, pelo fato que é mãe da cabeça, é mãe de muitos membros. A mãe do Cristo é a mãe dos membros de Cristo, porque a cabeça e o corpo é um só Cristo)

Parece-me que tenho provado os três nascimentos que prometi (...) sobre estas três grandes propriedades temos outras três muito mais próprias (...) Que unidos estes três nascimentos (...) todos e cada um deles se ordenam a declarar e persuadir a devoção do Rosário [Vieira, p. 646].

Partitio: Trata da obrigação dos Pretos em servir, venerar e invocar a Virgem com seu Rosário; em rezá-lo, a despeito do contínuo e grande trabalho em que se ocupam; e do ensinamento de quais são, entre os mistérios do Rosário, os que mais pertencem ao estado dos "Pretos" do Engenho.

\section{Narratio I: Servir, venerar e invocar a Virgem com o Rosário.}

Deveis dar infinitas graças a Deus (...) por vos ter tirado de terras, onde vossos pais e vós vivíeis como gentios (...) Fez Deus tanto caso de vós (...) que mil anos antes de vir ao mundo, o mandou escrever em seus livros [Vieira, p. 646]

"Coram illo procident Aethiopes"10

(Prostrar-se-ão diante Dele os Etíopes)

"Aethiopia prceveniet manus ejus Deo"11

(A Etiópia estenderá para Deus as suas mãos)

Estas duas profecias (...) cumpriram-se principalmente depois que os portugueses conquistaram a Etiópia ocidental (...) Deus antevendo esta vossa fé (...) vos escolheu de entre tantos outros (...) e vos trouxe ao grêmio da Igreja, para que lá, como vossos pais, não vos perdêsseis, e cá, como filhos seus, vos salvásseis [Vieira, p. 647]

\footnotetext{
${ }^{9}$ Guillielmus Abbas, ibidem.

${ }^{10}$ S1 71:9, apud Vieira, p. 646.

${ }^{11}$ S1 67:32, ibidem.
} 
"Factum est grande miraculum, ut Core pereunte, filii illius non perirent"'12

(Aconteceu um grande milagre, que, perecendo Coré, os seus filhos não pereceram)

Porque o maior milagre e a mais extraordinária mercê que Deus pode fazer aos filhos de pais rebeldes ao mesmo Deus, é que quando os pais se condenam, e vão ao inferno, eles não pereçam, e se salvem [Vieira, p. 648].

Narratio II: Trata da obrigação de rezar o Rosário a despeito do contínuo e grande trabalho em que se ocupam.

Vosso contínuo trabalho pode (...) servir de escusa (...) Direis que (...) as tarefas multiplicadas umas sobre as outras vos não deixam tempo (...) para rezar o Rosário (...). Davi (...) entre os Salmos que compôs, foram três particulares, aos quais deu por título: (...) Pro torcularibus filiis Core $^{13}$ (...) torcularia (...) significa todos aqueles lugares em que se espreme e tira o sumo dos frutos, como em Europa o vinho e o azeite, que lá se chamam lagares: e porque estes, em que no Brasil se faz o mesmo às canas doces (...) se chamam vulgarmente Engenhos (...) o fim e intento de Davi em compor e intitular aqueles Salmos (...) foi que (...) ajuntassem o trabalho com a oração (...) Não há trabalho, nem gênero de vida mais parecido à Cruz e Paixão de Cristo, que o vosso em um desses Engenhos [Vieira, p. 649-650].
"Torcular calcavi solus" ${ }^{14}$
(Eu sozinho pisei no lagar)
"Et de gentibus non est vir mecum"15
(E dos povos ninguém se achava comigo)

Vede vós quanto estimará agora que os que ontem foram gentios (...), lhe façam por imitação tão boa companhia! (...) Assim como no meio dos seus trabalhos e dos tormentos se não esqueceu o Senhor de sua piedosíssima Mãe, encomendando-a ao Discípulo amado, assim vos não haveis vós de esquecer da mesma Senhora (...) oferecendo-lhe a vossa (memória) [Vieira, p. 651-652]

${ }^{12} \mathrm{Nm}$ 26:10, apud Vieira, p. 647.

${ }^{13}$ Sl 83:1 [os lagares dos filhos de Coré].

${ }^{14}$ Jesus, referindo-se ao calvário em Is 63:3, apud Vieira, p. 651.

${ }^{15}$ Idem, ibidem. 
Narratio III: Trata do ensinamento de quais são, entre os mistérios do Rosário, os que mais pertencem ao estado dos "Pretos" do Engenho.

\section{"Dolores inferni circum dederunt me" 16}

(As angústias do inferno me cercaram)

E que coisa há na confusão deste mundo mais semelhante ao inferno, que qualquer destes vossos Engenhos? (...) mas se entre todo esse ruído, as vozes que se ouvirem, forem as do Rosário, orando e meditando os mistérios dolorosos, todo esse inferno se converterá em Paraíso (...) os homens, posto que pretos, em Anjos (...) é tal a virtude dos mistérios dolorosos (...) para os que orando os meditam (...) que o ferro se lhes converte em prata (...) a prisão em liberdade (...) o inferno em paraíso, e os mesmos homens, posto que pretos, em Anjos (...) os dolorosos são os que pertencem a vós, como os gozosos aos (...) vossos senhores (...) eles gozam os frutos de vossos trabalhos [Vieira, p. 655-657].

"Sic vos non vobis mellificatis apes" 17

(Assim, vós, não para vós fazeis o mel, abelhas)

Como agora (...) sois companheiros de Cristo nos mistérios dolorosos de sua Cruz; assim o sereis nos gloriosos de sua Ressurreição e Ascensão. Não é promessa minha senão de S. Paulo e texto expresso de Fé: Haeredes quidem Dei, cohaeredes autem Christi: si tamen compatimur, ut et conglorificemur ${ }^{18}(. .$.$) Todos querem ir à Glória$ (...) mas não querem padecer, nem ter parte na Cruz com Cristo (...) Mais inveja devem ter vossos senhores às vossas penas, do que vós aos seus gostos [Vieira, p. 657-658]

\section{Peroratio:}

Estes são, devotos do Rosário, os três motivos que nascem dos três nascimentos que vistes (...) nem podeis desejar maior honra nos vossos desprezos, nem maior alívio nos vossos trabalhos (...) Desta maneira se verifica (...) que o mesmo Jesus que se chama Cristo, não só uma senão três vezes nasceu de Maria: Maria de qua natus est Jesus, qui vocatur Christus. [Vieira, p. 658]

${ }^{16}$ Cristo, em Sl 17:6, apud Vieira, p. 655.

${ }^{17}$ Atribuído à Virgílio, apud Vieira, 657.

${ }^{18} \mathrm{Rm}$ 9:17 [Herdeiros de Deus e co-herdeiros de Cristo; se é certo que com ele padecemos, para que também com ele sejamos glorificados]. 


\section{Glossário $^{19}$}

ARGUMENTATIO - Argumentações utilizadas para a persuasão, podem ser confirmativas ou refutativas.

DISPOSITIO - Disposição das partes dentro do todo, a ordenação dos argumentos em ordem de progressão lógica.

EXÓRDIO - Parte introdutória do discurso na qual dominam os argumentos éticos e patéticos cuja função é tornar o auditório dócil, atento e benevolente.

INVENTIO - Busca das provas (argumentos) que constituem a substância do discurso.

NARRATIO - Exposição dos fatos referente à causa.

PARTITIO - Indicação do roteiro que o discurso irá percorrer, suas etapas. PERORATIO - É o fecho do discurso, abrange a recapitulação dos pontos mais contundentes com novo apelo ao ético e ao patético.

PROPOSITIO - Assinala o partido tomado pelo orador.

TITLE. Latin and rhetoric in the sermons of Vieira: sermon XIV of rosary

Abstract. Maria de qua natus est Jesus, qui vocatur Cristus is the epigraph of Sermon XIV of the Rosary, corpus of the research "the Latin as element of Rhetoric in the Sermons of the priest Antônio Vieira", whose partial results are presented here. Of the epigraph, the author extracts three born ones of Maria: Jesus, Saint John and the devoted "black colors", being the same mother, but the diverse childbirth; in one, exempt one of pain in the manger, another one, crossed - 'cruciabatur ut pariat' - in the mount when borns Rescuer and he earns, there, the other sons: 'Ecce fillius tuus', for Saint John and 'Populus Aethiopium hi fuerunt illc' for the "black colors" people. Of these, therefore, three respective obligations to love, to serve and to venerate the Virgin. I look for to demonstrate as the Latin citations all structuralize delineation rhetorical of Vieira, fundamental for accurate understanding.

KEYwords. Sermon; latin; rhetoric; Maria; "black colors" devoted.

${ }^{19}$ Obras consultadas: Heinrich LausBerg, Elementos de Retórica Literária, Lisboa, Calouste Gulbenkian, ${ }^{4} 1993$. Olvier Reboul, Introdução à Retórica, São Paulo, Martins Fontes, 2000. Dante Tringal, Introdução à Retórica, São Paulo, Duas Cidades. 1988. 